\title{
Effects of maternal age, parity and hemoglobin on neonatal stature and cord blood hemoglobin: an observational study
}

\author{
Namrata Tiwari ${ }^{1 *}$, Vinay Mishra ${ }^{2}$ \\ ${ }^{1}$ Department of Obstetrics and Gynecology, KEM Hospital, Parel, Mumbai, Maharashtra, India \\ ${ }^{2}$ Department of Pediatrics, Cuddles and Cure, Mulund, Mumbai, Maharashtra, India
}

Received: 28 November 2019

Revised: 13 December 2019

Accepted: 30 December 2019

\author{
*Correspondence: \\ Dr. Namrata Tiwari, \\ E-mail: dr.namrata28@gmail.com
}

Copyright: (c) the author(s), publisher and licensee Medip Academy. This is an open-access article distributed under the terms of the Creative Commons Attribution Non-Commercial License, which permits unrestricted non-commercial use, distribution, and reproduction in any medium, provided the original work is properly cited.

\begin{abstract}
Background: There is a large body of research both in India and abroad studying the effect of maternal age, parity and haemoglobin (in third trimester) on their infant's birth weight. The present study has been planned to evaluate these factors effects on their infant's stature(anthropometry) and cord blood haemoglobin.

Methods: Maternal background information, third trimester haemoglobin concentration, gestational age and number of children was obtained and recorded in semi-structured case proforma. 100 post-partum women and their newborns were studied in post-natal ward of a tertiary care hospital in an urban area. Maternal and neonatal data and anthropometric measurements were recorded in semi-structured case proforma.

Results: Of the 100 newborns, $43 \%$ were second born, followed by $35 \%$ first born, $18 \%$ third born and only $4 \%$ were fourth born by the order of their birth. Out of the 100 studied mothers $52 \%$ were anaemic as per the WHO criteria (Hb $<11 \mathrm{gm} \%$ ). Cord blood haemoglobin values decreased significantly as the order of birth increased. The cord blood haemoglobin of normal birth weight newborns is significantly higher as compared to that of low birth weight newborns. Cord blood haemoglobin concentrations shows strong statistical significance with maternal anaemia. The birth order of the child has a prominent inverse effect on the cord blood haemoglobin values.

Conclusions: There should nationwide improvement in the nutritional status of the girl child by dietary supplementations to improve the health of the generations to come. There should be proper birth spacing to prevent maternal and neonatal morbidities. Maternal anaemia needs early and aggressive treatment to minimize perinatal complications to both mother and the baby.
\end{abstract}

Keywords: Anthropometry, Haemoglobin, Maternal age, Maternal anaemia, Newborn, Parity

\section{INTRODUCTION}

The growth of a new-born infant is affected by many factors. The events that occur during prenatal, perinatal and post-natal periods have bearing on future growth and development of the new-born.But it is a universally accepted truth that adequate nutrition before and during pregnancy has the greatest potential for long term health of mother and the child. ${ }^{1}$ Thus, maternal nutrition is an important factor responsible not only for the health of the baby but also the child's long term growth. ${ }^{2}$ Therefore the understanding of maternal nutrition and foetal growth is critical. ${ }^{3}$ Assessment of maternal nutritional status relies upon maternal physical markers like pre-pregnancy weight, height, BMI, gestational weight gain etc. ${ }^{4,5}$

Birth weight plays an important role in infant mortality and morbidity, development, and future health of the child. ${ }^{6}$ World-wide, more than 20 million infants are born each year weighing less than $2500 \mathrm{~g}$, accounting for $17 \%$ of all births in the developing world. Low birth weight (LBW, birth weight $<2500 \mathrm{~g}$ ) leads to an impaired 
growth of the infant with its attendant risks of a higher mortality rate, increased morbidity impaired mental development and the risk of chronic adult disease. ${ }^{7,8}$ The causes of low birth weight and prematurity are complex and interdependent, but the anthropometry of the mother and her nutritional intake are thought to be among the most important.

Another important determinant of low birth weight and prematurity is maternal anaemia, most importantly nutritional due to iron deficiency. ${ }^{9,10}$

There is a large body of research both in India and abroad studying the effect of maternal nutritional markers on their infant's birth weight. However, association between other neonatal anthropometric indices and cord blood haemoglobin with maternal nutrition have been lacking prodding us to plan this study. The present study has been planned to evaluate the effects of maternal nutritional markers on their infant's anthropometry and cord blood haemoglobin.

Aims of the study was to study the effect of maternal nutritional markers on the anthropometry and cord blood haemoglobin concentration of their newborns.

Objectives to study the effect of -

- Maternal age and parity and

- Biochemical nutritional marker (third trimester haemoglobin concentration) on 1. Stature of their newborn and 2. cord blood haemoglobin of their newborn.

\section{METHODS}

This was an observational prospective study carried out in the post-natal ward of a tertiary care hospital in an urban area. Before the commencement of the study a clearance was obtained from the hospital's ethical committee.

After delivery, women were taken to the ward and an informed consent was obtained and those willing were enrolled for this study. All post-partum women and their newborns, fulfilling the inclusion criteria's were selected. A total of 100 mother-newborn pairs were enrolled over a period one year from July 2011 to June 2012.

\section{Inclusion criteria}

- Pre-term and term live birth neonate- mother pairs whose hospital stay exceeded 24 hours

- Newborns born by vaginal and caesarean delivery.

\section{Exclusion criteria}

- Unregistered and un-investigated mothers

- Mothers with diabetes mellitus, pregnancy induced hypertension and cardio-vascular disease
- Twin newborns

- Newborns having major congenital malformations.

Maternal background information, third trimester haemoglobin concentration, gestational age and number of children was obtained and recorded in semi-structured case proforma Gestational age was calculated from the last date of the menstrual cycle.

New-born weights were measured using electronic weighing scale to the nearest of $20 \mathrm{gm}$. Length, head circumference and chest circumference were measured within 48 hours after birth using non-stretchable measuring tape to the nearest of $0.5 \mathrm{~cm}$. Genders of the babies were recorded and Ponderal index of the newborns was calculated using formula Weight (gms)/Length $\left(\mathrm{cm}^{3}\right)$.

As per WHO criteria, mothers having $\mathrm{Hb}<11$ gm\% were considered anaemic and remaining were non-anaemic.

\section{Statistical analysis}

The data obtained was analysed using SPSS 20 software. Data was presented using percent, mean and standard deviation. The comparison between the groups was done using One Way Analysis of Variance for two groups. For more than two groups comparisons further post-hoc analysis was done using Tukey test. Pearson correlation coefficient was used for correlating the variables. P-value less than 0.05 was considered significant.

\section{RESULTS}

In the present study, out of the 100 newborns studied 56 were males and 44 were females.

A total 93 babies were delivered after 37 weeks of gestation (full-term) and 7 were delivered before 37 weeks of gestation (pre-term).

A total 64 of the 100 deliveries studied were conducted by normal vaginal route and rest 36 were Caesarean sections for various maternal or fetal indications.

A total 78 babies were born with birth weight of more than 2500 gm (normal birth weight, NBW) and 22 were born with birth weight of less than 2500 gm (low birth weight, LBW).

Out of the 78 normal birth weight (NBW) babies 47 were males and 31 were females as compared to 9 males and 13 females of the 22 low birth weight babies.

Of the 100 newborns, $43 \%$ were second born, followed by $35 \%$ first born, $18 \%$ third born and only $4 \%$ were fourth born by the order of their birth. Out of the 100 studied mothers $52 \%$ were anaemic as per the WHO criteria and the remaining $48 \%$ were non-anaemic mothers. 
The mean maternal ag was 28.07 years. The mean third trimester haemoglobin of the mothers evaluated in the study was $10.74 \mathrm{gm} \%$ (Table 1 and 2).

The means of the maternal characteristics of the studied population as described in Table 1 are as follows. The mean maternal age was 28.07 years.
Table 1: Age, anthropometric features and haemoglobin of mothers.

\begin{tabular}{|llll|}
\hline Maternal characteristics & Mean & Median & SD \\
\hline Maternal age (years) & 28.07 & 28.00 & 4.654 \\
\hline $\begin{array}{l}\text { Maternal haemoglobin } \\
\text { (gm\%) }\end{array}$ & 10.74 & 11.00 & 1.926 \\
\hline
\end{tabular}

Table 2: Comparisons of means (ANOVA) of maternal age and maternal haemoglobin according to the gestational age of newborns.

\begin{tabular}{|llll|}
\hline Maternal Characteristics (mean and SD) & Term $(\mathbf{n}=\mathbf{9 3})$ & Preterm $(\mathbf{n}=\mathbf{7})$ & Total $(\mathbf{n}=\mathbf{1 0 0})$ \\
\hline Maternal age (years) & $28.22 \pm 4.63$ & $26.14 \pm 4.88$ & $28.07 \pm 4.65$ \\
\hline Maternal haemoglobin $(\mathrm{gm} \%)$ & $10.73 \pm 1.99$ & $10.77 \pm 0.74$ & $10.73 \pm 1.92$ \\
\hline
\end{tabular}

Table 3: Comparisons of means (ANOVA) of neonatal anthropometry and cord blood haemoglobin according to their gestational age.

\begin{tabular}{|llll|}
\hline New-born characteristics $($ mean and SD) & Term $(\mathbf{n}=\mathbf{9 3})$ & Preterm $(\mathbf{n}=\mathbf{7})$ & Total $(\mathbf{n}=\mathbf{1 0 0})$ \\
\hline Birth weight $(\mathrm{gm})$ & $2.885 .91 \pm 398.82$ & $2192.86 \pm 343.30$ & $2837.40 \pm 431.90$ \\
\hline Length $(\mathrm{cm})$ & $50.42 \pm 2.74$ & $47.86 \pm 1.35$ & $50.24 \pm 2.49$ \\
\hline Head circumference $(\mathrm{cm})$ & $33.08 \pm 1.93$ & $29.71 \pm 0.49$ & $32.84 \pm 2.06$ \\
\hline Chest circumference $(\mathrm{cm})$ & $31.10 \pm 1.90$ & $28.14 \pm 1.46$ & $30.89 \pm 2.01$ \\
\hline Ponderal index & $2.26 \pm 0.29$ & $1.98 \pm 0.17$ & $2.24 \pm 0.29$ \\
\hline Cord blood haemoglobin $(\mathrm{gm} \%)$ & $15.20 \pm 1.64$ & $13.49 \pm 0.489$ & $15.08 \pm 1.65$ \\
\hline
\end{tabular}

Table 4: Comparisons of means (ANOVA) of maternal haemoglobin, neonatal anthropometric features and cord blood haemoglobin according to birth order.

\begin{tabular}{|lllllll|}
\hline Birth order & $\mathbf{1}(\mathbf{n}=\mathbf{3 5})$ & $\mathbf{2}(\mathbf{n}=\mathbf{4 3})$ & $\mathbf{3}(\mathbf{n}=\mathbf{1 8})$ & $\mathbf{4}(\mathbf{n}=\mathbf{4})$ & Total $(\mathbf{n}=\mathbf{1 0 0})$ & P-value \\
\hline Maternal haemoglobin $(\mathrm{gm} \%)$ & 11.0314 & 10.6953 & 10.7278 & 8.6500 & 10.7370 & 0.135 \\
\hline Birth weight $(\mathrm{gm})$ & 2786.86 & 2901.86 & 2787.22 & 2812.50 & 2837.40 & 0.645 \\
\hline Length $(\mathrm{cm})$ & 50.11 & 50.53 & 50.00 & 49.25 & 50.24 & 0.690 \\
\hline Head circumference $(\mathrm{cm})$ & 32.87 & 32.69 & 33.11 & 33.00 & 32.84 & 0.907 \\
\hline Chest circumference $(\mathrm{cm})$ & 30.78 & 30.88 & 31.19 & 30.55 & 30.89 & 0.893 \\
\hline Ponderal index & 2.22 & 2.24 & 2.28 & 2.34 & 2.24 & 0.826 \\
\hline Cord blood haemoglobin $(\mathrm{gm} \%)$ & 15.78 & 15.00 & 14.19 & 13.83 & 15.08 & $0.002 *$ \\
\hline
\end{tabular}

Table 5: Pearson correlation coefficients (P-values in brackets) between maternal haemoglobin and neonatal parameters (anthropometry and cord blood haemoglobin).

\begin{tabular}{|lllllll|}
\hline Parameters & $\begin{array}{l}\text { Birth weight } \\
(\mathrm{kg})\end{array}$ & Length $(\mathrm{cm})$ & $\begin{array}{l}\mathrm{HC} \\
(\mathrm{cm})\end{array}$ & $\begin{array}{l}\mathrm{CC} \\
(\mathrm{cm})\end{array}$ & $\begin{array}{l}\text { Ponderal } \\
\text { Index }\end{array}$ & $\begin{array}{l}\text { Cord blood } \\
\text { Hb }(\mathrm{gm} \%)\end{array}$ \\
\hline $\begin{array}{l}\text { Mothers } \mathrm{Hb} \\
(\mathrm{gm} \%)\end{array}$ & $0.368(0.000) *$ & $0.134(0.185)$ & $0.382(0.000) *$ & $0.412(0.000) *$ & $0.290(0.003) *$ & $0.458(0.000) *$ \\
\hline *Statistically significant values & & & &
\end{tabular}

*Statistically significant values

Statistical significance was not obtained as the two groups were not comparable.

The mean birth weight of the studied newborns in the present study was $2837.40 \mathrm{gm}$ with a standard deviation of 431.896. The mean length, head circumference and chest circumference were $50.24 \mathrm{~cm}, 32.84 \mathrm{~cm}$ and 30.89 $\mathrm{cm}$ respectively which were in normal range. The mean
Ponderal index for the studied population was 2.24. The mean cord blood haemoglobin of newborns was 15.08 gm\% with a standard deviation of 1.648 which was in normal range.

From Table 3, it was evident that the means of birth weight, length, head circumference, chest circumference, Ponderal Index and cord blood haemoglobin in full term 
newborns was higher than that of the preterm newborns. Statistical significance was not obtained as the two groups were not comparable.

On comparing the means of maternal haemoglobin, neonatal anthropometric features and cord blood haemoglobin according to birth order on analysis of variance it is evident that cord blood haemoglobin values decreased as the order of birth increased and this value is statistically significant $(\mathrm{p}=0.002)^{*}$. There are no significant associations between order of birth and other variables mentioned in the table above (Table 4 ).

There is statistically significant positive correlation between mother's third trimester haemoglobin and birth weight $(\mathrm{P}=0.000)^{*}$, head circumference $(\mathrm{p}=0.000)^{*}$, chest circumference $(\mathrm{p}=0.000)^{*}$, Ponderal Index $(\mathrm{p}=$ $0.003)^{*}$ and cord blood haemoglobin $(\mathrm{P}=0.000)^{*}$ of the newborn (Table 5).
On correlating mother's third trimester haemoglobin with cord blood haemoglobin values in the newborns, there was very strong statistically significant $(P=0.000)$ positive correlation between the two variables suggesting maternal anaemia causes a significant fall in cord blood haemoglobin values.

There is statistically significant $(\mathrm{p}=0.002)^{*}$ negative correlation between order of birth and cord blood haemoglobin (Table 6).

The cord blood haemoglobin of normal birth weight newborns is significantly higher as compared to that of low birth weight newborns. This comparison has a strong statistical significance $(\mathrm{p}=0.000) *($ Table 7$)$.

Table 6: Pearson correlation coefficients ( $P$-values in brackets) between order of birth and neonatal parameters (anthropometry and cord blood haemoglobin).

\begin{tabular}{|c|c|c|c|c|c|c|}
\hline Parameters & $\begin{array}{l}\text { Birth weight } \\
\text { (kg) }\end{array}$ & Length (cm) & $\begin{array}{l}\mathrm{HC} \\
(\mathrm{cm})\end{array}$ & $\begin{array}{l}\mathrm{CC} \\
(\mathrm{cm})\end{array}$ & $\begin{array}{l}\text { Ponderal } \\
\text { Index }\end{array}$ & $\begin{array}{l}\text { Cord blood } \\
\text { Hb }(\mathrm{gm} \%)\end{array}$ \\
\hline Birth order & $0.019(0.853)$ & $-0.038(0.705)$ & $0.030(0.766)$ & $0.039(0.697)$ & $0.091(0.368)$ & $-0.373(0.000)^{*}$ \\
\hline
\end{tabular}

Table 7: Comparisons of means (ANOVA) of maternal age, height, BMI and haemoglobin according to the birth weight of the newborns.

\begin{tabular}{|lllll|}
\hline Maternal characteristics (mean and SD) & LBW $(\mathbf{n}=\mathbf{2 2})$ & NBW $(\mathbf{n}=\mathbf{7 8})$ & Total & p-value Sig $<\mathbf{0 . 0 5}$ \\
\hline Maternal age (years) & $28.33 \pm 4.94$ & $28.03 \pm 4.60$ & $28.07 \pm 4.65$ & 0.859 \\
\hline Maternal Haemoglobin (gm\%) & $9.25 \pm 2.33$ & $11.16 \pm 1.58$ & $10.74 \pm 1.93$ & $0.000^{*}$ \\
\hline
\end{tabular}

Table 8: Comparisons of means (ANOVA) of neonatal anthropometry and cord blood haemoglobin with respect to maternal third trimester haemoglobin.

\begin{tabular}{|lllll|}
\hline Parameters $($ means and SD) & Maternal anemia $(\mathbf{H b}<\mathbf{1 1})$ & No anemia $(\mathbf{H b}>\mathbf{1 1})$ & Total & p-value \\
\hline Birth weight & $2774.62 \pm 457.76$ & $2905.42 \pm 395.53$ & $2837.40 \pm 431.90$ & 0.131 \\
\hline Length & $50.46 \pm 2.28$ & $50.00 \pm 2.70$ & $50.24 \pm 2.49$ & 0.357 \\
\hline Head circumference & $32.66 \pm 2.18$ & $33.04 \pm 1.91$ & $32.84 \pm 2.06$ & 0.361 \\
\hline Chest circumference & $30.50 \pm 2.42$ & $31.31 \pm 1.35$ & $30.89 \pm 2.01$ & $0.046^{*}$ \\
\hline Ponderal index & $2.16 \pm 0.25$ & $2.33 \pm 0.30$ & $2.24 \pm 0.29$ & $0.003 * *$ \\
\hline Cord blood hemoglobin & $14.53 \pm 1.55$ & $15.68 \pm 1.55$ & $15.08 \pm 1.65$ & $0.000^{* * *}$ \\
\hline
\end{tabular}

*Statistically significant values

Also, the cord blood haemoglobin concentrations of the low birth weight babies were significantly lower than that of the normal birth weight babies (Table 7).

On comparing the means of neonatal anthropometry and cord blood haemoglobin with respect to maternal third trimester haemoglobin it is found that mothers with anaemia $(\mathrm{Hb}<11 \mathrm{gm} \%)$ have significantly lower chest circumference $(\mathrm{P}=0.046)^{*}$, Ponderal index $(0.003)^{* *}$ and cord blood haemoglobin concentrations $(\mathrm{p}=$ 0.000 )*** (Table 8).

\section{DISCUSSION}

Anthropometry is defined as the scientific study of the measurements and proportions of the human body. ${ }^{11}$ The use of anthropometry in medicine, more specifically in child development gives an early clue to nutritional disorders. Anthropometry has been since long used as a 
marker of well-being of a newborn infant. It not only suggests the general well-being of the neonate, but also suggests pattern of growth during the intra-uterine life. The present study attempts at studying the effect of maternal nutritional markers on neonatal stature and haemoglobin.

Birth weight is an important indicator of child survival. ${ }^{12}$ The health of the mother affects the birth weight. It has been associated with socio-demographic, clinical, racial, hereditary, personal and even seasonal and geographical factors. ${ }^{13-16}$ A normal baby weighs around $3.3 \mathrm{~kg}$ at birth and loses around $10 \%$ of birth weight during first 7 days of life, which is regained by the $10^{\text {th }}$ day. ${ }^{17}$

Depending upon the weight, the neonates are termed as low birth weight $(<2500 \mathrm{gm})$, very low birth weight $(<$ $1500 \mathrm{gm})$ or extremely low birth weight $(<1000 \mathrm{gm}){ }^{18}$ Birth weight is a good indicator of intra-uterine growth of a foetus. It also affects adult life. ${ }^{19}$

The WHO global action report on preterm birth 2012 puts the world-wide incidence of preterm births ( $<37$ weeks) at $11.1 \%$, Elshibly and Schmalisch in 2008 in a study of 1000 births in Sudan, reported preterm birth rate of $5.7 \% .^{18,19}$ It is comparable to our study which showed the same as $7 \%$. This was probably due to the better antenatal services and nutrition offered to the mothers predominantly residing in an urban area.

The incidence of low birth weight as calculated by our study is $22 \%$ which was lower than the national standards; however $68 \%$ of the low birth weight babies were full term, complying with the national figures. In developing countries like ours, this can be attributed to intra-uterine growth retardation due to variety of factors, of which, one of the most important is poor maternal nutrition. ${ }^{20}$

Our study found significant fall in cord blood haemoglobin values with increase in the birth order (parity) (Table 4). Correlation between the birth order and cord blood haemoglobin showed very strong statistical significance $(\mathrm{P}=0.000)$ between the two variables. This can be attributed to our finding of maternal anaemia with increasing parity (Table 5), though not statistically significant. Elshibly and Schmalisch reported significantly increased birth weight with increasing birth order as have also demonstrated by various other studies. ${ }^{19,20}$ Our study failed to demonstrate any significant correlation between order of birth and any of the studied neonatal anthropometric parameters like birth weight, length, head circumference, chest circumference and ponderal index (Table 6).

The present study revealed that more than half $(52 \%)$ of the pregnant mothers were anaemic. All the mothers with low birth weight babies were anaemic as per the WHO cut-off values for anaemia in pregnancy ( $\mathrm{Hb}<11.0$ gm\%). The third trimester haemoglobin values of the mothers with low birth weight babies were significantly lower than that of mothers with normal birth weight babies (Table 7). ${ }^{21}$ An Indian study by authors, Kumar $\mathrm{KJ}$, Asha $\mathrm{N}$ et al reported similar incidence of maternal anaemia as in the present study. They found increased incidence of low birth weight if the mothers were anaemic in the third trimester of pregnancy. ${ }^{22}$ Our study also reported a similar trend.

Like in all other studies, third trimester maternal haemoglobin not only showed very strong positive correlation with the birth weight in our study, but it also revealed significant effects over other neonatal anthropometric markers like head circumference, chest circumference and Ponderal Index, as well as on cord blood haemoglobin values.

\section{CONCLUSION}

Widespread nutrition deprivation among women perpetuates an inter-generational cycle of nutrition deprivation in children. Undernourished girls grow up to become undernourished women who give birth to a new generation of undernourished children. This intergenerational cycle of undernutrition transmitted from mothers to children greatly impacts on India's present and future. The anaemic mothers give birth to babies who are not only low birth weight but also have less stature. This shows the overall hampering effect maternal anaemia has on fetal growth.

Maternal age, parity and anemia has a very significant impact on the neonatal anthropometric parameters. Thus, it is concluded that maternal nutrition not only during gestation, but also during the crucial periods of growth in the pre-child bearing age group has a very significant impact on fetal development.

Funding: No funding sources Conflict of interest: None declared

Ethical approval: The study was approved by the Institutional Ethics Committee

\section{REFERENCES}

1. Singh M, Jain S, Choudhary M. Dietary adequacy of pregnant women of four districts of Rajasthan. J Hum Ecol. 2009;21:161-5.

2. Jackson AA, Robinson SM. Dietary guideline for Pregnancy. Public Health Nutr. 2001;10:623-30.

3. Rao S, Yajnik CS, Kanade A, Fall CH, Margetts $\mathrm{BM}$, et.al. Intake of micronutrient-rich foods in rural Indian mothers is associated with the size of their babies at birth: Pune maternal nutrition study. J Nutr. 2001;131:1217-24.

4. Nahar S, Massie-Taylor CGN, Ara Begum H. Maternal anthropometry as a predictor of birth weight. Pub Health Nutr. 2007;10:965-70. 
5. World Health Organisation. Maternal anthropometry and pregnancy outcomes: a WHO collaborative study. Bull World Health Organ. 1995;73(1):1-98.

6. Godfrey KM, Barker DJ. Fetal nutrition and adult disease. Am J Clin Nutr. 2000;71:1344S-52S.

7. Ashworth A. Effects of intrauterine growth retardation on mortality and morbidity in infants and young children. Eur J Clin Nutr. 1998;52(1):S34S42.

8. Grantham-McGregor SM. Small for gestational age, term babies, in the first six years of life. Eur J Clin Nutr. 1998;52(1):S59-S64.

9. Rasmussen KM, Stoltzfus RJ. New evidence that iron supplementation during pregnancy improves birth weight: new scientific questions. Am J Clin Nutr. 2003;78:673-4.

10. Preziosi P, Prual A, Galan P, Daouda H, Boureima $\mathrm{H}$, Hercberg S. Effect of iron supplementation on the iron status of pregnant women: consequences for the newborn. Am J Clin Nutr. 1997;66:1178-82.

11. Lakshmanaswamy A. Growth and development. In: Clinical Paediatrics History taking and Case discussion, $3^{\text {rd }}$ ed. New Delhi: Wolters Kluwer; 2011:98.

12. Huque F, Hussain Z. Detection of low birth weight newborn babies by anhthropometric measurements in Bangladesh. Indian J Pediatr. 1991;58:223-31.

13. Macfarlane A. Altitude and birth weight. Commentary. J Pediatr. 1987;111:842-44.

14. Jones KP. Ethnic variations in birth-weight-a study of British, Chinese and Gurkha babies. JR Army Med Crops. 1987;133:746-74.

15. Hort KP. Seasonal variation of birth-weight in Bangladesh. Ann Trop Pediatr. 1987;7:66-71.

16. Roberts SB, Paul AA, Cole TJ, Whitehead RG. Seasonal changes in activity, birth weight and lactational performance in rural Gambian women. Trans Royal Society Trop Med Hyg. 1982;76(5):668-78.

17. Agrawal M. Normal growth and development. In: Textbook of Pediatrics, $1^{\text {st }}$ ed. Mumbai: Bhalani Publishers; 2009:7.

18. Chang HH, Larson J, Blencowe H, Spong CY, Howson CP, et al. Preventing preterm births: Analysis of trends and potential reductions with interventions in 39 countries with very high human development index. The Lancet. 2013;381(9862):223-34.

19. Elshibly EM, Schmalisch G. The effect of maternal anthropometric characteristics and social factors on gestational age and birth weight in Sudanese newborn infants. BMC Public Health. 2008;8:244.

20. Kumar S, Kumar HN, Jayaram S, Kotian MS. Determinants of low birth weight: a case control study in a district hospital in Karnataka. Indian $\mathbf{J}$ Pediatr. 2010;77:87-9.

21. Deshmukh JS, Motghare, Zodpey SP. Low birth weight and associated maternal factors in an urban area. Indian Pediatr. 1998;35:33-6.

22. Kumar KJ, Asha N, Murthy DS, Sujata MS, Manjunath VG. Maternal anemia in various trimesters and its effect on newborn weight and maturity: an observational study. Int $\mathbf{J}$ Prev Med. 2013;4(2):193-9.

Cite this article as: Tiwari N, Mishra V. Effects of maternal age, parity and hemoglobin on neonatal stature and cord blood hemoglobin: an observational study. Int J Reprod Contracept Obstet Gynecol 2020;9:488-93. 